\title{
Assessment of Photosynthetic Pigments and Dust Load in Selected Avenue Plants of Saharanpur and Herbertpur Areas of India
}

\section{Abid Qadir ${ }^{1}$ Arshad Bhat ${ }^{2 \rtimes(D)}$ Iqra Qureshi ${ }^{3}$}

'Research Scholar, Department of Environmental Studies, The Glocal University, India. Email: abidqadir12@gmail.com Tel: +91-7006259141

Post-Doctoral Research Associate, Rajiv Gandhi Chair in Contemporary Studies on Livelihood and Food Security, Sher-e-Kashmir University of Agricultural Sciences and Technology of Kashmir.

Email:bhatarshado9@gmail.com Tel: +91-9797268144

${ }^{3}$ Toung Professional, Department of Food Technology, Central Institute of Temperate Horticulture, Rangreth Srinagar.

Email: igraqureshi840@gmail.com Tel:+91-7006276101

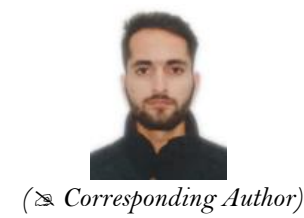

\section{Abstract}

The paper depicts impact of $\mathrm{SO}_{2}, \mathrm{NO}_{2}$, ozone and $\mathrm{CO}$ in chosen road plants of Saharanpur and Herbertpur regions in Indian dominion. Plant species falling in and around the area of modern territory and street side were chosen for examining purpose. Different morphological attributes and impact of business and vehicular residue on chlorophyll shade were contemplated and noticed the impact of residue molecule on development of the plant species (Ficus religiosa, Mangifera indica). In the examination the impacts of residue on chosen tree species was noticed and which will help in overseeing advancement of green belt to lessen the air contamination in the investigation area. Treatment with dust fundamentally expanded the fixation on leaves and the impacts were more extreme in significant degree of residue medicines. Contrasted with control, chlorophyll and porphyrin in substance were essentially diminished in the residue treated gatherings. This investigation propounds that business and vehicular residue statements affect photosynthetic shades, with broad impacts on development and improvement of plant.

Keywords: Assessment, Chlorophyll, Photosynthesis, Pollution, Pigmentation, Dust load, Impact.

Citation | Abid Qadir; Arshad Bhat; Iqra Qureshi (2021). Assessment of Photosynthetic Pigments and Dust Load in Selected Avenue Plants of Saharanpur and Herbertpur Areas of India Asian Review of Environmental and Earth Sciences, 8(1): 30-37.

History:

Received: 21 June 2021

Revised: 23 July 2021

Accepted: 18 August 2021

Published: 14 September 202

Licensed: This work is licensed under a Creative Commons Attribution 3.0 License $(\mathrm{ccc})$

Publisher: Asian Online Journal Publishing Group
Acknowledgement: All authors contributed to the conception and design of the study.

Funding: This study received no specific financial support.

Competing Interests: The authors declare that they have no conflict of interests.

Transparency: The authors confirm that the manuscript is an honest, accurate, and transparent account of the study was reported; that no vital features of the study have been omitted; and that any discrepancies from the features of the study have been omitte
study as planned have been explained.

Ethical: This study follows all ethical practices during writing.

\section{Contents}

1. Introduction

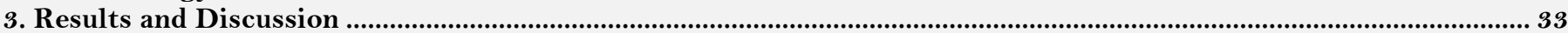

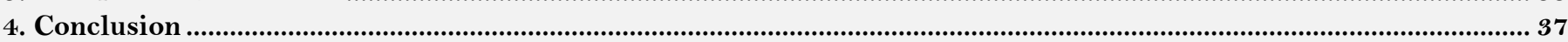

References. 


\section{Contribution of this paper to the literature}

This study contributes to existing literature by assessing and estimating dirt load on leaf floor of flowers of Ficus religiosa, Mangifera indica through dirt taking pictures potential of road plants of Saharanpur metropolis and Herbertpur and also assess effect of pollutants on photosynthetic pigments (chlorophyll a, chlorophyll b, and carotenoids). The paper will of immense help for the policy makers and planners to reduce the emission of dust particulates from the industries and the vehicular transport around the study area, and will further opens a gateway for the researchers to study impact of dust on the aquatic and terrestrial animals.

\section{Introduction}

Metropolitan air contamination has become a genuine natural issue for trees and other living habitats (Chauhan \& Joshi, 2008). The vast majority of Indian urban areas are influencing with the presence of high centralizations of poisonous vaporous and particulate toxins because of industrialization, gravely kept up helpless streets, helpless support of vehicles, employments of powers with poor natural execution and absence of mindfulness (Joshi \& Chauhan, 2008). Encompassing air contamination in a few huge urban communities of India is among the most noteworthy on the planet (Agrawal, 2005). As per a gauge, dust contaminations involve around $40 \%$ of absolute air contamination issue in India (Chauhan, 2008). In city locales assorted kinds of contamination alongside $\mathrm{SO}_{\mathrm{x}}, \mathrm{NO}_{\mathrm{x}}$, ozone $\left(\mathrm{O}_{3}\right)$, carbon monoxide and dangerous characteristic mixtures are dispatched on account of those anthropogenic exercises, which can be delivering a ruinous effect on vegetation. Contamination is a significant problem influencing the world. It is accessible in masses of structures which incorporate air, land, and water contaminations and structures a few reasserts which incorporate industry, business, and transportation here and there you may see it, anyway various sorts are imperceptible to the uncovered eye. The particulates and vaporous contaminations, alone and in blend, can make genuine mishap the general physiology of plants (Anda, 1986; Ashenden \& Williams, 1980; Mejstř́ik, 1980; Seinfeld, 1975). It has been accounted that vaporous structures are consumed by the leaves, while the particulate structures are assimilated through the external surface of the plants. Influenced plants shows some regular impacts like chlorophyll, corruption, restraint in photosynthesis and diminishing plant development (Davison \& Blakemore, 1976). Plant reaction to air contamination can be utilized to evaluate the nature of air that may give early admonition signs of air contamination patterns (Wagh, Shukla, Tambe, \& Ingle, 2006). Plants tremendous give a huge leaf region to impingement, ingestion and amassing of air poisons to diminish the contamination level noticeable all around climate (Escobedo et al., 2008), with a different degree for various species (Hove, Bossen, De Bok, \& Hooijmaijers, 1999). Unfavorable impacts of air toxins on plants with decrease in photosynthetic shades and yield have been appeared by changed laborers in various harvests (Davison \& Blakemore, 1976; Farmer, 1993; Lerman, 1972; Meyerowitz et al., 1987; Rajput \& Agrawal, 2005; Saquib \& Khan, 1999) air contaminations has been characterized as an additional tension on vegetation given that they every now and again answer to air disease with inside the equivalent way as they answer to dry spell and distinctive environmental factors Air toxins has outrageous results at the human wellbeing. Contingent upon the degree of exposure and the type of toxin exhaled in, those results can shift, beginning from simple signs like hacking and the contamination of the breathing parcel to intense circumstances like bronchial hypersensitivities and chronic lung illness. It in this back drop the present study was carried out to study the negative effects of dust deposition on photosynthetic pigments (chlorophyll a, chlorophyll b, carotenoids) and on leaf surface.

\section{Methodology}

For the analysis purpose, Saharanpur and Herbertpur were taken as unit of analysis Figure $1 \& 2$.

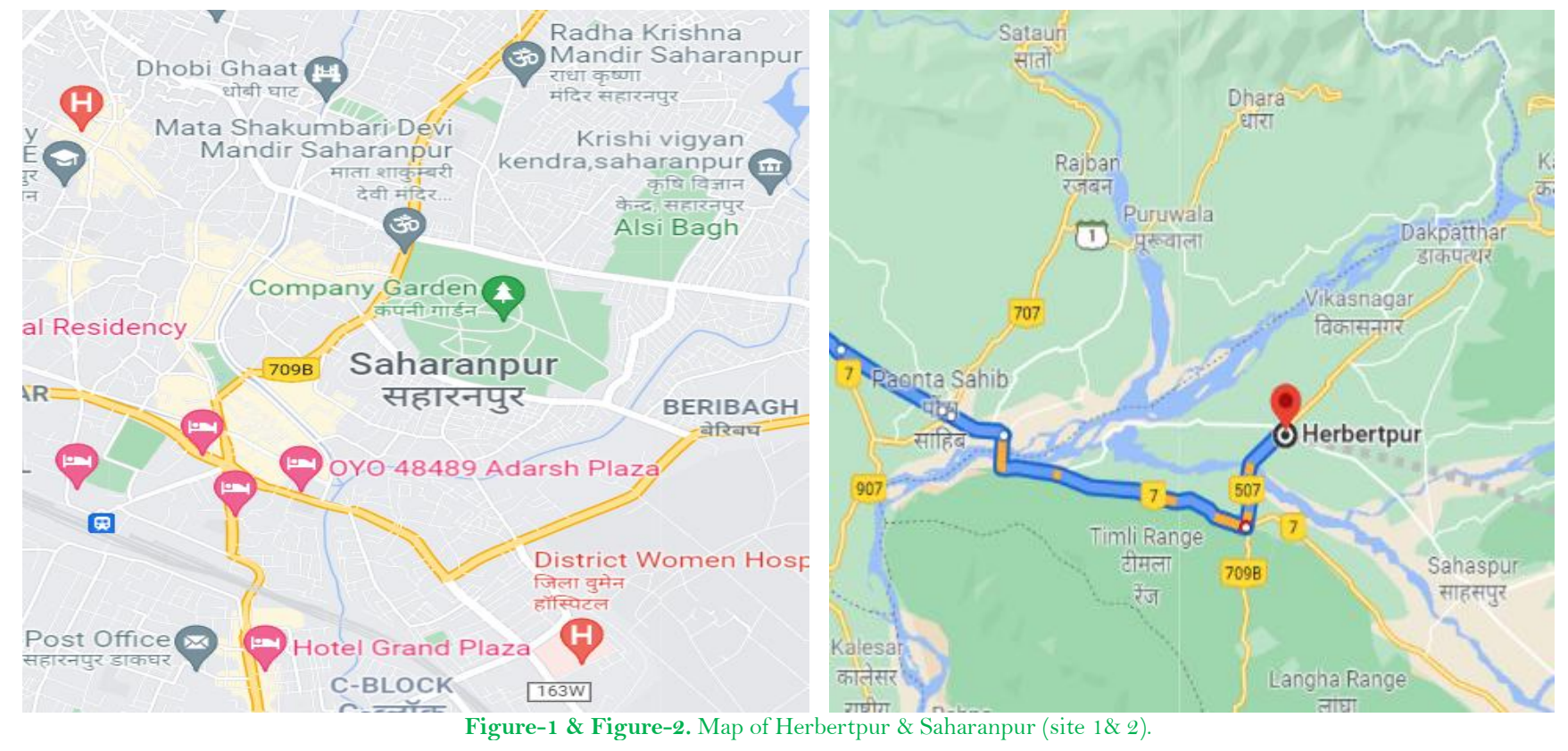

\subsection{Site Selection}

On the idea of excessive site visitor's zone, excessive dust generating supply and plant variety following sites had been decided on:

- Site-1 Herbertpur (Dehradun).

- Site-2 Saharanpur city (Uttar Pradesh).

Site 1:- 
- Herbertpur is a city and a nagar panchayat in Dehradun district with inside the Indian country of Uttarakhand. It is positioned at the financial institution of river Asan and the call of the vicinity is at the call of Sir Herbert the antique call of Herbertpur is chuodpur. It is positioned at $30.450 \mathrm{~N}$ It has a median elevation of 427 meters (1,401 feet). NHW passes thru Vikasnagar. It ends in Yamunotri. There is large site visitors rush on this region because of Chandigarh Dehradun toll road heaps of cars are strolling on this region everywhere in the day.

Site 2:-

- Saharanpur city (district) is the north maximum a part of Uttar Pradesh, India and is near the foothills of Shivalik range. It lies in the northern a part of Doab region. It is an agricultural predominant region. Saharanpur is located at $29.97^{\circ} \mathrm{N} 77.55^{\circ} \mathrm{E}$, approximately a hundred thirty $\mathrm{km}$ south-southeast from Chandigarh and a hundred and seventy $\mathrm{km}$ north-northeast from Delhi. It has a median elevation of 284 meters. It is fantastically polluted and densely populated because of the human beings dwelling there. There are considerable numbers of factories which might be the reason of highest pollutants there. The motion of site visitors is so excessive, this is the reason for highest polluted surroundings there.

2.2. Identification of Important Dust Arresting Plant Indicator Species

The identity of the plant species Table 1 changed into undertaken at respective sites that have very excessive herbal ability of particulates and dust debris from ambient air close to creation regions and at excessive site visitor's junctions with vehicle motion due to their morphological and anatomical. The identity of plant life changed into undertaken with the help of literature, monographs and taxonomical books.

Table-1. Plant species decided on for study

\begin{tabular}{c|c|c|c}
\hline S.No. & Botanical Name & Common Name & Family \\
\hline 1 & Mangifera indica & Mango & Anacardiaceae \\
\hline 2 & Saraca indica & Peepal & Moraceae \\
\hline
\end{tabular}

2.3. Dust Load

Dust is produced with the aid of using subdivision of strong cloth through mechanical movements or in nature. Anthropogenic emission is generated in the course of grinding or milling of materials, in the course of switch of finely divided cloth in addition from agriculture, forestry and production activities. The massive the particle diameter, they generally tend to settle faster. Particle massive than $50 \mu \mathrm{m}$ settle rapidly. Due to non-stop publicity of flora to dust debris, which gets deposited at the leaf floor and that is termed as 'dust load'.

Dust load is calculated with the aid of using following components:

Dust load (in $\left.\mathrm{mg} / \mathrm{cm}^{2}\right)=$ Dust load on leaf (in mg)

Surface area of leaf $\mathrm{cm}^{2}$

2.4. Plant's Leaf Analysis

The leaf samples from the chosen plant species of both sites were accumulated, washed well and weighed. Morphological and biochemical traits of selected plant species were carried out by following popular procedures.

\subsubsection{Morphological Analysis}

Morphological characters like forms of leaves, association of leaves, floor and texture of leaves, form and length of leaves were observed.

\subsubsection{Biochemical Analysis}

\subsubsection{Chlorophyll Content}

Reagent: $80 \%$ aetone $(v / v)$ chilled: Chlorophyll estimation was carried out with the aid of using Arnon approach. For this $0.1 \mathrm{gm}$. leaf pattern was beaten in $5 \mathrm{ml}$ of $80 \%$ acetone (chilled) after which centrifuged at 10,000rpm for 10 minutes. Pallets was discarded and supernatant was taken out. Absorbances were taken at 480nm, 510nm, 645 and $663 \mathrm{~nm}$. Acetone was used as blank.

Various concentrations in $\mathrm{mg} \mathrm{g}^{-1} \mathrm{fr}$, wt. was calculated with the aid of the subsequent formulae given by Maclachlan and Zalik (1963) for chlorophyll:

Chlorophyll a $\left(\mathrm{mg} \mathrm{g}^{-1} \mathrm{f} . \mathrm{w}\right)=\frac{12.7\left(A_{663}\right)-2.63\left(A_{645}\right) \times v}{D \times(1000) \times W}$

Chlorophyll b $\left(\mathrm{mg} \mathrm{g}^{-1} \mathrm{f} . \mathrm{w}\right)=\frac{22.9\left(A_{645}\right)-4.68\left(A_{663}\right) \times v}{D \times(1000) \times W}$

Total Chlorophyll (mg g-1 f.w) = Chlorophyll a + Chlorophyll b

The Carotenoid content material was predicted by usage of the formulae of Duxbm'y and Yentsch (1956)

Carotenoid $\left(\mathrm{mg} \mathrm{g}^{-1} \mathrm{f} . \mathrm{w}\right)=\frac{7.6\left(A_{480}\right)-1.49\left(A_{510}\right) \times v}{D \times(1000) \times W}$

Where, $\mathrm{A}=$ absorbance

$\mathrm{V}=$ quantity of the pattern $(\mathrm{ml})$

$\mathrm{D}=$ distance traveled with the aid of using the mild path $(=1 \mathrm{~cm})$

$\mathrm{W}=$ weight of the leaf $(\mathrm{g})$

\subsubsection{Leaf Dust Accumulation}

Newly matured leaves of the chosen tree species were taken for recording their dust load. The higher surfaces of the leaves were wiped with exceptional brushes which were later tagged for identification. The leaves were stored for twenty-four hours for dust accumulation. After 24 hours leaf dust turn was collected within the pre weighed butter paper baggage with the help of high-quality brush. After taking the statistics for dust accumulation, the leaves were lessen from petiole, saved in ice field and brought to the laboratory for further analysis. The 
amount of dust collected on leaves was weighed on top pan virtual balance and calculated with the help of following equation:

$\mathrm{W}=\frac{W 2-W 1}{A}$

Where;

$\mathrm{W}=$ dust content material (gm-2)

$\mathrm{W}_{1}=$ initial weight of butter paper bag

$\mathrm{W} 2=$ final weight of butter paper bag with dust

$\mathrm{A}=$ widespread location

\section{Results and Discussion}

3.1. Determination of Dust Load in Selected Plants

The dust trapping ability of plant life were taken as a parameter for enhancing and tracking air quality. By calculating dust load on plant life were categorized into unique classes like excessive dust ability, mild dust shooting ability and occasional dust shooting ability. This categorization of plant life in keeping with their performance of shooting dust is beneficial in choice of road plant life in selected site covers of Saharanpur. It changed into a business in addition to excessive site visitor's vicinity. The variety of heavy cars in step with day is greater compared to different regions because of Chandigarh, Dehradun highway. Pollution density was highest their because of heavy site visitors. These are the most important reason of pollutants on this vicinity.

Selected site (S1) covers Herbertpur. This is a place that's much less polluted than Saharanpur. Because there is much less motion of site visitors there and additionally there is much less variety of creation locations there. The plant whose layout shown in Table 2 is usual place at each decided on sites. Among those plant life species the most dust load changed into recorded with the aid of using Ficusreligiosa tree than Mangiferaindica tree at each sites. The results revealed that Saharanpur site changed into greater polluted than Herbertpur site, because of heavy site visitor's motion and establishment of industries in the area. The results further revealed that the Ficusreligiosa tree captures greater dust than Mangiferaindica tree Figure $3 \& 4$.

\begin{tabular}{|c|c|c|c|c|c|c|c|c|}
\hline & \multicolumn{8}{|c|}{ Sites } \\
\hline & \multicolumn{4}{|c|}{ Herbertpur (S1) } & \multicolumn{4}{|c|}{ Saharanpur (S2) } \\
\hline & R1 & $\mathbf{R 2}$ & R3 & $\mathbf{R 4}$ & R1 & R2 & R3 & R4 \\
\hline 0.015 & 0.275 & 0.055 & 0.01 & 0.03 & 0.00 & 0.06 & 0.00 & $\mathrm{O}$ \\
\hline 0.025 & 0.25 & 0.11 & 0.02 & 0.055 & 0.375 & 0.035 & 0.05 & 0.05 \\
\hline
\end{tabular}
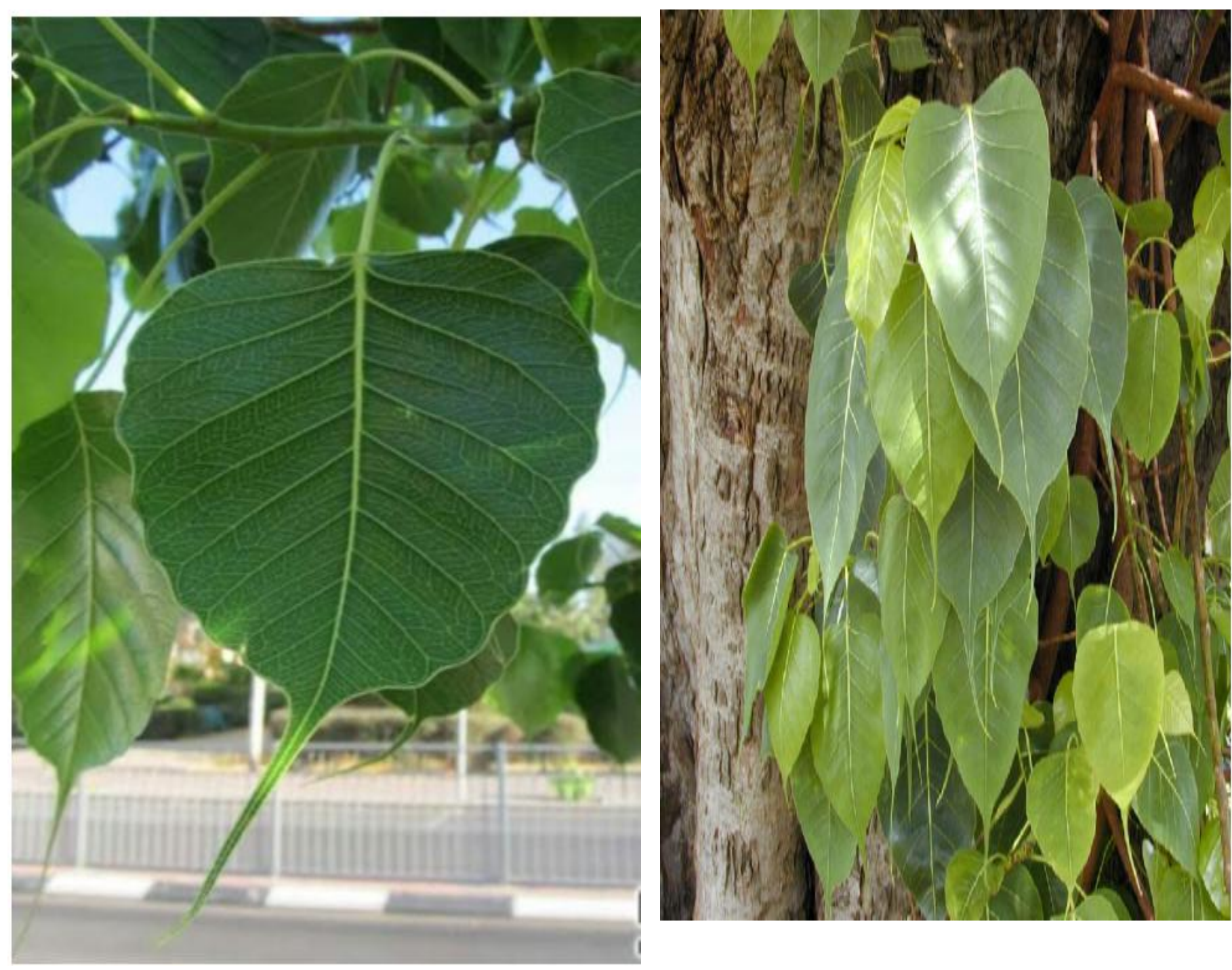

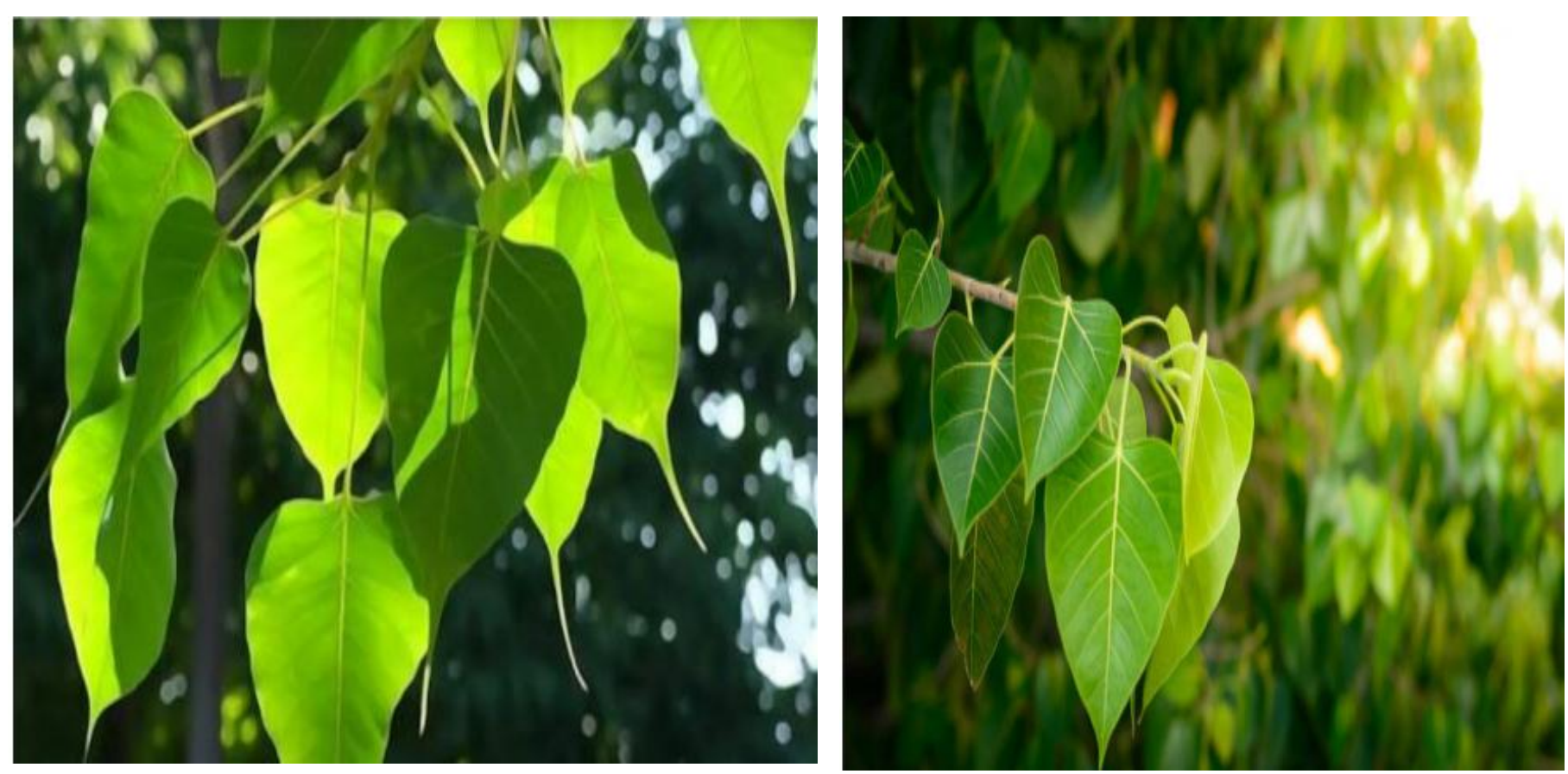

Figure-3. Dust deposition on Peepal plants at two different sites.
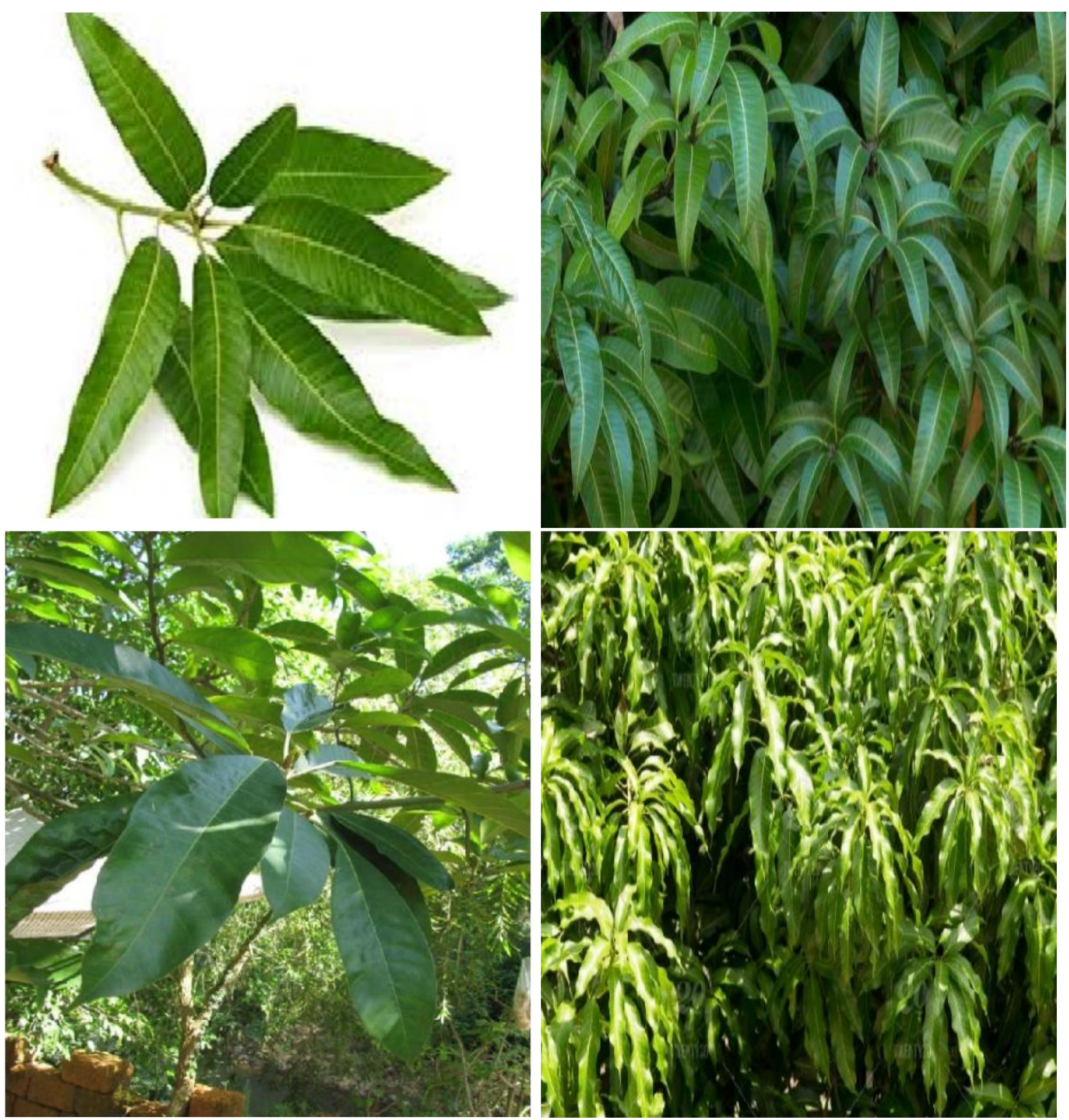

Figure-4. Dust deposition on Mango plants at two different sites.

Peepal tree >Mango tree: A superb correlation has been observed among the dust trapping and micro roughness of the full leaf vicinity. Roughness of top floor may be described because of presence of ridges and 
furrows fashioned with the aid of using epidermal mobileular lining, vein projections, stomata included with wax rings, cuticular arches, hairs or scales and sunken position.

Mangiferaindica (Mango tree) is called flowering plant in sumac and poison ivy own circle of relatives Anacardiaceae. It is a big fruit tree, able to developing a top and crown width of approximately 30 meters and trunk circumference of greater than 3.7 meters. It is likewise a terrible species for dust trapping. The leaf of Mango tree is lengthy and narrow. Thus this parameter fails to make it an awesome species for dust loading. Hence it must be planted in such vicinity in which dust pollutants are much less like in parks and gardens.

Ficusreligiosa (Peepal tree) recognized for non-secular purpose. They are lengthy and huge trees. It is a great specie for dust trapping. The leaves of Peepal tree are very huge Figure 5. Therefore, with these characteristics, such species are ideal for trapping of dust. Hence it must be planted close to the roads and on locations in which pollutants stage is excessive.
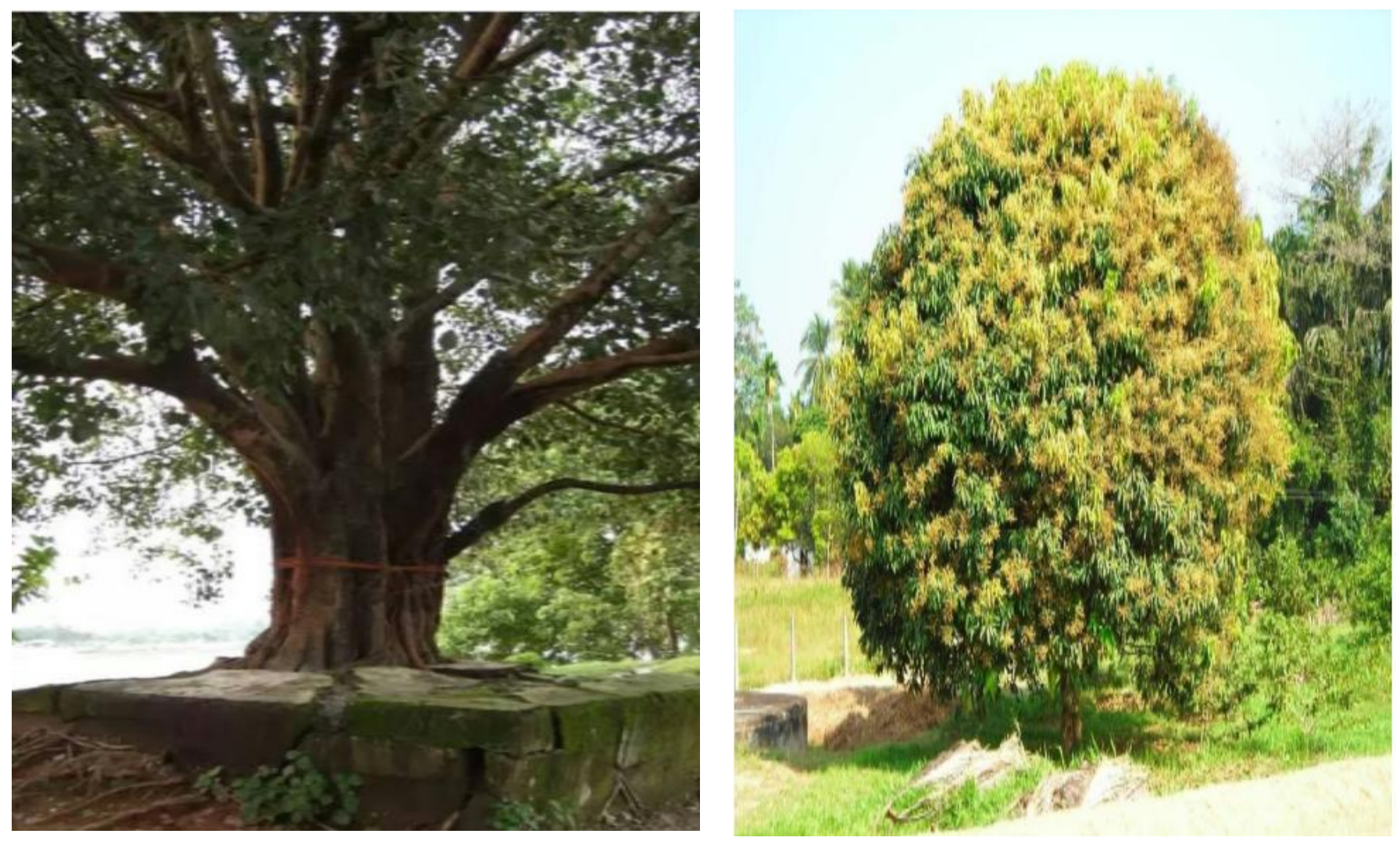

Figure-5. Dust deposition on common selected plants at two different sites.

3.2. Leaf Surface Morphology

3.2.1. Structure of Leaf

i. Structure of leaf lamina: unique kinds of leaves tend to have qualification in various components in their surfaces. A few kinds of leaves have additional floor pressure or harshness than various leaves, which can likewise affect tenacity or molecule solvency. The various diverse morphological capacities are components obligated for dust shooting wonders through methods for leaves Table 3.

\begin{tabular}{c|c|c|c|c|c|c}
\hline Plants & Leaf Habit & Leaf Surface & Lamina Shape + Margin & $\begin{array}{c}\text { Lamina } \\
\text { Apex }\end{array}$ & Venation & Phyllotaxy \\
\hline M.indica & Tropical & Broad, Rounded. & $\begin{array}{c}\text { Flat, lateral, Entire, } \\
\text { undulate, } \\
\text { smooth }\end{array}$ & Acute & Reticulate & Alternate \\
\hline f.religiosa & Deciduous & $\begin{array}{c}\text { Glabrous, } \\
\text { Glaucou, Fleshy }\end{array}$ & Oval or Elliptical, Entire & Blunt & Reticulate & Opposite \\
\hline
\end{tabular}

Leaves may be of various shapes, sizes and might have specific sorts of surfaces and textures. Larger the vicinity extra dust could be attenuated at the floor. Venation may be defined because the association of veins in a leaf. Phyllotaxy is the association of the leaf at the stem. There are a number of essential traits which can supply a clue which plant species may be used for development of air-exceptional of surroundings and environment.

ii. Length and breadth of leaf and petiole: size, shape, texture and floor of leaves play a completely essential function in dust shooting mechanism. Larger the leaf vicinity more could be its performance to seize dust. The above desk indicates that Mangiferaindica and Ficusreligiosa are having pretty big in comparison to other plants. Due to big floor vicinity of those plants, they are taken into consideration as best road plants. Due to big floor vicinity of leaves of those plants, they are taken into consideration to be beneficial in enhancing air-exceptional like Bargad tree Table 4. Hairs gift at the leaf floor allows dust debris to paste on it, consequently on this manner leaf adsorbs dust and contributes in discount of dust pollution.

Table-4. Length and Breadth of selected plants and leaves.

\begin{tabular}{c|c|c|c}
\hline Plant selected & Length of leaf (in $\mathbf{~ m})$ & Length of petiole (in $\mathbf{c m})$ & Breadth of leaf (in cm) \\
\hline Mangifera indica & 24 & 1 & 4.2 \\
\hline Ficus religiosa & 18.2 & 1 & 10.6 \\
\hline
\end{tabular}




\subsubsection{Biochemical Analysis}

i. Chlorophyll content: Chlorophyll is a pigment observed inside the cells of leaves that is shaped simplest in the presence of mild and is the substance that shades plant life green, chlorophyll is contained in chloroplasts and has the belongings of taking pictures mild power. Chlorophyll molecules are mainly organized in and round picture graph structures which are embedded with inside the thylakoid membranes of chloroplasts. In those complexes serves number one functions. The characteristic of the sizable majority of chlorophyll (as much as numerous hundred molecules according to photosystem) is to take in mild and switch that mild power through resonance power switch to a selected chlorophyll pair inside the response middle of the photosystem. The presently universal photosystem gadgets are Photosystem I and Photosystem II, that have their personal wonderful response middle chlorophylls, named P680 and these pigments are named after the wavelength (in nanometers) of their red-top absorption most. These pigments are referred to as accent pigments or chlorophyll ' $a$ ' and chlorophyll 'b'. The identity, characteristic and spectral residences of the varieties of chlorophyll in every photosystem are wonderful and decided through every different and the protein shape surrounding them.

Carotenoids are tetraterpenoid natural pigments which are obviously taking place inside the chloroplasts and chromoplasts of plant life. There are over six hundred acknowledged carotenoids, they were break up into classes, xanthophylls (which include oxygen) and carotenes which might be only hydrocarbons, and include no Carotenoids in widespread take in blue mild. They serve key roles in plant life, they take in mild power to be used in photosynthesis, and that they defend chlorophyll from picture graph damage. The photosynthetic pigment content materials on plant life at sites are estimated in Table 5.

Table-5. Chlorophyll a (mg g-1f.w) content in sampled leaves.

\begin{tabular}{|c|c|c|c|c|c|c|c|c|}
\hline \multirow{3}{*}{ Plant species } & \multicolumn{8}{|c|}{ SITES } \\
\hline & \multicolumn{4}{|c|}{ Site 1} & \multicolumn{4}{|c|}{ Site2 } \\
\hline & $\mathbf{R 1}$ & R2 & R3 & R4 & $\mathbf{R 1}$ & R2 & R3 & R4 \\
\hline Mangifera indica & 0.018 & 0.055 & 0.038 & 0.048 & 0.066 & 0.080 & 0.045 & 0.040 \\
\hline Ficus religiosa & 0.058 & 0.093 & 0.075 & 0.045 & 0.062 & 0.076 & 0.040 & 0.078 \\
\hline
\end{tabular}

The chlorophyll content material of site 1 is observed to be greater than site 2 which became uncovered to dust. The reducing order of chlorophyll and carotenoid content material on sites are offered below:

Site $1<$ Site 2

It may be due to the motive that site 2 is more populated as it is a business place and there site visitors may be very excessive compared to site 1 , that is why the plant life on this place has greater chlorophyll content material compared to site 2. At site 2, the most general chlorophyll content material became recorded in Ficusreligiosa accompanied through Mangiferaindica. It suggests that Ficus religiosa (Peepal) are pollutants tolerant species. Same sample of end result has been recorded at different site Table 6 .

Table-6. Chlorophyll b ( $\left.\mathrm{mg} \mathrm{g}^{-1} \mathrm{f} . \mathrm{w}\right)$ content in sampled leaves

\begin{tabular}{|c|c|c|c|c|c|c|c|c|}
\hline \multirow{3}{*}{ Plant species } & \multicolumn{8}{|c|}{ SITES } \\
\hline & \multicolumn{4}{|c|}{ Site 1} & \multicolumn{4}{|c|}{ Site 2} \\
\hline & R1 & $\mathrm{R} 2$ & R3 & R4 & R1 & R2 & R3 & R4 \\
\hline Mangifera indica & 0.031 & 0.038 & 0.052 & 0.083 & 0.116 & 0.069 & 0.067 & 0.054 \\
\hline Ficus religiosa & 0.098 & 0.047 & 0.139 & 0.104 & 0.105 & 0.055 & 0.057 & 0.141 \\
\hline
\end{tabular}

It has been recorded that dust deposition influences photosynthetic pigments adversely. Researchers have recorded discount in chlorophyll content material beneath air pollutants; the shading consequences, because of deposition of suspended particulate count at the leaf floor is probably accountable for this lower with inside the awareness of chlorophyll in polluted place. They additionally pronounced discount carotenoid in plant life beneath air pollutants. Chloroplast pigments have been proven to be very touchy to diverse environmental influences. Changes in chlorophyll and carotenoid content material have been investigated through numerous researchers. This is possible due to deceleration of the biosynthetic techniques as opposed to chlorophyll 'a'. In the present analysis it is observed that chlorophyll 'a' content material of leaves became better than chlorophyll 'b' at selected sites. Reduced chlorophyll 'b' content material compared to chlorophyll 'a' confirmed that chlorophyll 'b' is greater touchy than chlorophyll ' $a$ '. The Table 7 shows total chlorophyll content in both the sites. Carotenoid content material is reporting better at site 1 compared to site 2 . In site 1 it is far most in Ficusreligiosa accompanied through Mangiferaindica and identical sample of end result has been recorded at site 2 Table 8.

Table-7. Total Chlorophyll (mg g-1 f.w) content in sampled leaves.

\begin{tabular}{|c|c|c|c|c|c|c|c|c|}
\hline \multirow[b]{3}{*}{ Plant species } & \multicolumn{8}{|c|}{ SITES } \\
\hline & \multicolumn{4}{|c|}{ Site 1} & \multicolumn{4}{|c|}{ Site 2} \\
\hline & R1 & R2 & R3 & R4 & R1 & R2 & R3 & R4 \\
\hline Mangifera indica & 0.049 & 0.093 & 0.090 & 0.131 & 0.182 & 0.149 & 0.112 & 0.094 \\
\hline Ficus religiosa & 0.156 & 0.14 & 0.214 & 0.149 & 0.167 & 0.131 & 0.097 & 0.219 \\
\hline
\end{tabular}

Table-8. Carotenoid ( $\left.\mathrm{mg} \mathrm{g}^{-1} \mathrm{f} . \mathrm{w}\right)$ content in sampled leaves.

\begin{tabular}{|c|c|c|c|c|c|c|c|c|}
\hline \multirow[b]{3}{*}{ Plant species } & \multicolumn{8}{|c|}{ SITES } \\
\hline & \multicolumn{4}{|c|}{ Site 1} & \multicolumn{4}{|c|}{ Site 2} \\
\hline & R1 & R2 & R3 & R4 & R1 & R2 & R3 & R4 \\
\hline Mangifera indica & 0.030 & 0.046 & 0.009 & 0.057 & 0.050 & 0.067 & 0.057 & 0.062 \\
\hline Ficus religiosa & 0.069 & 0.059 & 0.034 & 0.062 & 0.014 & 0.017 & 0.061 & 0.024 \\
\hline
\end{tabular}




\section{Conclusion}

An extensive misfortune in all out chlorophyll in the leaves of plants presented to contamination upholds the contention that the chloroplast is the essential site of assault via air contaminations like $\mathrm{SO}_{2}, \mathrm{NO}_{2}$, ozone and CO. This examination shows that openness to particulate statement modify the plant development without changing any actual changes to the plant. Reaction of plants towards air is being surveyed via air contamination resilience record. Some plant species and assortments are delicate to such an extent that they can be advantageously utilized as natural pointers or on the other hand screens of explicit toxins. Other than concentrate on sway of mechanical residue particles on chlorophyll color of leaves, further exploration is going on different boundaries to know the Air Pollution Tolerant lists of the plants here which can additionally help organizer in dealing with the metropolitan urban areas by creating green belt advancement to decrease the air contamination. Taking everything into account, the particulate contamination at various chosen regions was essentially because of development work, mechanical work and vehicles. Biochemical boundaries like chlorophyll 'a' chlorophyll 'b' \& carotenoids in chosen plants were determined, these boundaries are considered as contamination markers. Assessment of these boundaries assumes a significant part in demonstrating the degree of residue contamination.

\section{References}

Agrawal, M. (2005). Effects of air pollution on agriculture: An issue of national concern. National Academy Science Letters, 28(3/4), 93-106.

Anda, A. (1986). Effect of cement kiln dust on the radiation balance and yields of plants. Environmental Pollution Series A, Ecological and Biological, 4O(3), 249-256. Available at: https://doi.org/10.1016/0143-1471(86)90099-1.

Ashenden, T., \& Williams, I. (1980). Growth reductions in Lolium multiflorum Lam. and Phleum pratense L. As a result of $\mathrm{SO} 2$ and $\mathrm{NO} 2$ pollution. Environmental Pollution Series A, Ecological and Biological, 21(2), 131-139. Available at: https://doi.org/10.1016/01431471(80)90041-0.

Chauhan, A., \& Joshi, P. (2008). Effect of ambient air pollution on photosynthetic pigments on some selected trees in urban area. Ecology Environment and Conservations, 14(4), 23-27.

Chauhan., A. (2008). Impact of dust pollution on photosynthetic pigments of some selected trees grown at nearby of stone-crushers. Environment Conservation Journal, 9(3), 11-13.

Davison, A. F., \& Blakemore, J. (1976). In: Mansfield TA (ed) Effects of air pollutions on plants. Cambridge University Press: Cambridge.

Davison, A. W., \& Blakemore, J. (1976). In: Effects of air pollutions on plants (Ed. T.A. Mansfield). Cambridge University Press: Bridge, UK.

Duxbm'y, A. C., \& Yentsch, C. S. (1956). Plankton pigment nomographs, tecmlical Report No. 54 The Lignin Fraction of Marine Sediments, By Richard G. Bader. Office of Naval Research. Project Nr 083-012. University of Vashington, Departnent of Oceinography Seattle, 5 , Washington.

Escobedo, F. J., Wagner, J. E., Nowak, D. J., De la Maza, C. L., Rodriguez, M., \& Crane, D. E. (2008). Analyzing the cost effectiveness of Santiago, Chile's policy of using urban forests to improve air quality. Journal of Environmental Management, 86(1), $148-157$. Available at: https://doi.org/10.1016/j.jenvman.2006.11.029.

Farmer, A. M. (1993). The effects of dust on vegetation-a review. Environmental Pollution, 79(1), 63-75. Available at: https://doi.org/10.1016/0269-7491(93)90179-r.

Hove, V. L., Bossen, M., De Bok, F., \& Hooijmaijers, C. (1999). The uptake of O3 by poplar leaves: The impact of a long-term exposure to low O3-concentrations. Atmospheric Environment, 33(6), 907-917. Available at: https://doi.org/10.1016/s 1352-2310(98)00259-3.

Joshi, P. C., \& Chauhan, A. (2008). Performance of locally grown rice plants (Oryza sativa L.) exposed to air pollutants in a rapidly growing industrial area of district Haridwar, Uttarakhand, India. Life Science Journal, 5(3), 41-45.

Lerman, S. (1972). Cement-kiln dust and the bean plant (Phaseolus vulgaris L. Black Valentine Var.) in-depth investigations into plant morphology, physiology and pathology. Ph.D. Dissertation, University of California.

Maclachlan, S., \& Zalik, S. (1963). Plastid structure, chlorophyll concentration and free amino acid composition of a chlorophyll mutant of barley. Candan Journal of Botany, 41(7), 1053-1062. Available at: https://doi.org/10.1139/b63-088.

Mejstř́k, V. (1980). The influence of low SO2 concentrations on growth reduction of Nicotiana tabacum L. cv. Samsun and Cucumis sativus L. cv. Unikat. Environmental Pollution Series A, Ecological and Biological, 21(1), 73-76. Available at: https://doi.org/10.1016/01431471(80)90034-3.

Meyerowitz, A., Olszyk, D. M., Kats, G., Dawson, P. J., Wolf, J., \& Thompson, C. R. (1987). Effects of SO2 on physiology, elemental content and injury development of winter wheat. Agriculture, Ecosystems E Environment, 20(1), 37-47. Available at: https://doi.org/10.1016/0167-8809(87)90026-0.

Rajput, M., \& Agrawal, M. (2005). Biomonitoring of air pollution in a seasonally dry tropical suburban area using wheat transplants. Environmental Monitoring and Assessment, 101(1), 39-53.

Saquib, M., \& Khan, F. (1999). Air pollution impacts on the growth and reproductive behaviour of mustard. Journal of Environmental Biology, 20(2), 107-110.

Seinfeld, J. H. (1975). Air pollution: Physical and chemical properties. U.S.A: Mc. Graw Hill.

Wagh, N., Shukla, P. V., Tambe, S. B., \& Ingle, S. (2006). Biological monitoring of roadside plants exposed to vehicular pollution in Jalgaon city. Journal of Environmental Biology, 37(2), 419-42 1. 